\title{
Social Media to Foster Self-Organized Participa- tory Learning for Disengaged Learners
}

\author{
http://dx.doi.org/10.3991/ijac.v6i1.2211 \\ Pieter de Vries, Thieme Hennis \\ Delft University of Technology, Delft, Netherlands
}

\begin{abstract}
The reAct project described in this paper is an innovative learning approach developed and used to remotivate the disengaged from education and learning to connect to lifelong learning practices. These youngsters constitute a considerable social problem in Europe and the aim of the project is to find ways to recover the intrinsic motivation to learn and thereby improve the opportunities for participation. Key in this innovative strategy is selforganized learning, the learner in control of the learning process. The paper starts with an introduction on the challenge these dropouts pose to the society at large and the learning strategy developed to cope with this matter. The usage of media in the methodology is crucial and links to the concept of a user-configurable Personal Learning Environment (PLE). The main research issues are: can reAct change the attitude, what are the benefits and drawbacks of this self-organized learning approach and do the ICT tools support these processes. This paper covers the first half of the project and reflects on the first rather positive experiences.
\end{abstract}

Index Terms-Disengaged learners, Drop Outs, Social Media, Self-Organized learning, reAct project, Participatory Design

\section{INTRODUCTION}

The percentage of young people that do not complete compulsory education constitutes a considerable social problem in Europe. The urgency of this problem is revealed by the individual, social and economic consequences. These youngsters have a higher risk of unemployment, face a higher risk of poverty, participate less in re-training, rely more on social support throughout their lives and tend to participate less in elections or other democratic processes [1]. The percentage of young people that do not complete compulsory education is especially high in the South where in Portugal 35,4\%, Spain 31\%, Italy $19,7 \%$, and Greece $14,8 \%$ of the students drop out of school. But also countries like Holland 11,4\% and Austria $10,1 \%$ are faced with young people leaving school without a certificate [2].

To prevent disconnection at an early age most European countries have developed training programs to address the problems of this group with the objective of either their entry into jobs or reentry into the education system. These programs often offer some kind of extrinsic motivation, payment or the possibility of a job at the end. In most instances the motivation to learn is not addressed and the effect of these programs has shown to be rather limited [1].
Research shows that more flexible education and training systems with a variety of recognized learning pathways and combined with individual and school-level support offer more educational opportunities and therefore better chances of diminishing the risk of early school leave [3], [4], [5]. It is difficult though in traditional classroom and training settings to include the basic metacognitive and critical skills that would allow these learners to function autonomously in the current society and the labor market. This problem is made worse because these learners not only failed to learn, but have also forgotten how to learn, and tend to show a lack of interest in education in general.

This paper is about a methodology that has been developed in the framework of the European reAct project, an abbreviation for reactivating teachers and learners. ReAct deals with the needs of the dropouts in an attempt to improve the prospects and the employability of these learners, and to develop the skills of their teachers and trainers, in an area which is key to the success namely motivation.

The methodology should help demotivated learners to return to learning using Social media in a setting where they create their own projects working together with others from different countries in a self-organized way and coached by teachers [6]. The most important ICT tools that were chosen by learners during the first pilot include Facebook, Google Docs and Google+ Hangout, Prezi, and YouTube. In the following sections, we will highlight some of the exemplary uses of social media and describe their benefits and drawbacks.

\section{THE REACT PROJECT}

ReAct is a transnational European project that has been approved under Key Action 3: Information and communication technology of the Life Long learning program of the European Union.

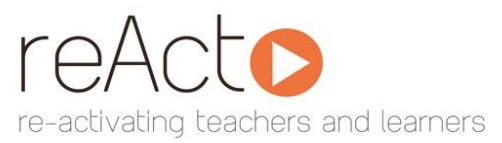

Figure 1. The reAct logo

Core in the project is the development of the 'reAct methodology' aiming at the use of a collection of ICT tools loosely linked in a virtual environment similar to social networks. It is user-configurable, based on the concept of the Personal Learning Environment (PLE) [7]. The design of specific methodological activities and 
strategies are aimed to develop intrinsic motivation in students, through personal involvement in significant creative tasks for the person and through interaction with other students [7]. Implementing a new approach though requires attention on the learners needs but also, vitally, to those of the teachers who implement the methodology, and the integration of the approach into existing curriculum bound formal school systems, to the extent that the teachers themselves constitute a prime target group.

The fundamental goal of the reAct Project is to pilot and experiment changes in pedagogical approaches of non-formal education. It aims at reducing the number of dropouts through leveraging motivation and agency of learners, in particular the development of skills that allow them to carry on learning throughout their lives. Developing ways to facilitate these is vital for lifelong learning practice in Europe [9].

\section{A. The Objectives}

The aim of the reAct methodology is to establish the conditions favorable for the experiments to take place and for the students to achieve the following.

- A change of attitude. The aim is for the learners to change from being passive subjects, an attitude very much instilled by the educational system throughout their childhood and youth, to being active. To effect this change the aim is to propose that they participate in creative activities, defined and directed by themselves with relevance for their personal life.

- Open minds. It would help to broaden their perspectives and let them discover other experiences and points of view of people living in other environments. European mobility initiatives have shown the benefits of this kind of activity.

- Teach them to learn. This includes developing cognitive skills and critical thinking skills that enable them to cope independently and autonomously with social and labor demands.

\section{B. The Methodology}

The methodology focuses on participatory design, collaboration, and creativity and learner autonomy as potential keys to the reactivation of the interest of learners who have not completed their education. It is based on investigation and consolidated processes, taken from informal learning, in which students "discover" by doing what motivates them, and through this process take a number of cognitive skills that allow them to act autonomously, tackling and understanding the learning situations as new opportunities [6].

To prepare for the development of the methodology there was a needs analysis performed as an initial study of the profiles of students in the institutions participating in the project, in order to adapt the activities and tools that were proposed in each environment to their abilities and needs. Once this study was done, a toolkit was put together, including a collection of social tools (Web 2.0) based on the concept of the Personal Learning Environment.

\section{The Organization}

A consortium of seven partners from six European Countries carries out the reAct project with extensive experience in education and training in Europe and detailed knowledge of the issues the project seeks to address. The countries are Spain, Italy, Portugal, Greece, Austria and the Netherlands. The partners are national and regional public administrations (SERVEF, CNO ESDICA), institutions related to the educational system (TU DELFT) and vocational training centers (KEK KRONOS, TR2000, TIBS, BFI TIROL), focusing on the training of young and adult unemployed and especially the use of new technologies in the field of education and training.

\section{The relevance}

From a European perspective the following can depict the relevance of the project.

- Develop an innovative methodological experience with a European impact.

- Enhance enrichment and exchange of experiences during the project between governments, training institutions and students from different European countries that share the same problems in training and employment contexts.

- Establish partnerships between different European countries to allow the continuation of transnational work and cooperation, after the end of the project.

- Promote motivation of students (especially early school leavers), through the development of creative tasks, motivating and enabling them to improve their personal and professional development.

- Involve European teachers in a methodology that combines innovative learning strategies, through the use of information technologies and communication technologies (ICTs).

\section{E. The Research Approach}

The international dimension of the project with very different locations and institutions required a layered research approach that depended on an active involvement of all the partners. Therefor an evaluation framework was developed to allow for a collaborative research action using an array of procedures. The involvement of the reAct partners comprised specific responsibilities:

- Interviews with teachers: The reAct partners effectuate pre-structured interviews with the teachers involved. The researching partner provides the necessary interview formats and questions

- Surveys amongst students: The reAct partners distribute survey instruments provided by the researching partner to the teachers and students.

- Regular interviews with the researching partner: The reAct partners have regular online interviews in which the progress of activities will be evaluated.

\section{F. Use of Social Media to improve collaboration}

In order to improve communication between partners, and increase participation of teachers in the project, various social media were used. Most importantly, the partner collaboration could not have been so effective without the use of Google Hangouts and Google Docs. Google Hangouts can be used to organize synchronous web-meetings including video-chat and integration of various apps, including Google Docs. Weekly meetings were prepared on Google Docs, and the agenda and notes were discussed in real-time while we were all able to work 
on it. Other documents, such as evaluation documents, were also discussed and edited in real-time.

Google Groups (mailing list) and a closed Facebook group (not for students) were used to maintain communication with teachers, who were a bit hesitant to interact actively on Google Groups, but were more active on Facebook.

\section{THE LEARNING METHODOLOGY}

The reAct learning strategy is the result of a substantive investigation that involved all partners, interviews with schools, teachers, and project leaders who have adopted innovative learning approaches. In addition a literature research was executed including the analysis of several case studies on alternative approaches to learning. The methodology has then been drafted collaboratively in several stages of creation and resulted in the 'ReAct Methodological Approach Guidelines’ [8]. A summary of this document is available at www.reactproject.eu.

The methodology is associated with an assembly of different resources, new developments and insights in education and the field of learning technologies [10].

\section{A. The essentials}

Learner Centred Approach: The teacher should facilitate students to learn, instead of providing content as prescribed by the curriculum. Content is not a top priority, but the student's participation and self-organisation.

- Fostering Motivation: Motivation is a key factor for drop out students; teachers therefor need to provide learning opportunities that suit students' interest, even if these do not seem to have any relationship with the original goals of the course.

- Group Oriented Activities: Learning can be seen as a process of manipulating data and information to give meaning by communication with others.

- Using Technology: The added value of Technology for learning resides in access to (a) resources, (b) information retrieval tools (c) sharing knowledge (d) communication tools, and (e) designing or creating multimedia content. Technology also introduces a new form of knowledge and pedagogy based on the idea that knowledge is distributed across a network of connections and that learning consists of the ability to construct and traverse those networks.

- Professional Development of Teachers: This development needs to be an integral part of the methodological design. Teachers do not change their pedagogy overnight, of course. This is why training of teachers in the reAct project is a continuous activity along the project duration.

\section{B. The Seven Pedagogical Principles}

Based on the experiences and observations in several related projects, and taking into account the local contexts, the following seven guiding principles are fundamental to the reAct project. In this context ICT is considered omnipresent and critical. Not as an aim in itself, but as a tool for a different and better way of learning that fits the overall objective of the reAct project to enable the students' participation and self-organization under all circumstances [8].
The principles are:

1. Trust: students and teachers must become confident that their ideas, contributions and comments are treated with respect, online as well as offline. Fostering trust will engender self-esteem of the students who have most of the time a poor image of one self as far as learning is concerned.

2. Challenging: students and teachers get motivated to learn when they experience or are faced with challenging, but manageable assignments. Teachers must ensure learning environments that offer the context in which students can adopt personal or group challenges. Teachers should address topics to study they consider relevant to research. Hence, assignments teacher suggest should be negotiable, or assignments should come from students themselves and teachers should enable students to define the relevance related to the learning goals set out at the beginning of the course.

3. Self-organized: we must put more trust in the hands of students to guide their own learning. Within the boundaries and restrictions of each individual pilot, teachers must try to allow as much self-organization and self-directed learning as possible. This requires not only a different way of thinking, but most important: patience. Asking questions is a better approach than providing assignments.

4. Collaboration: Students take great interest in working with others. Teachers support collaboration through group-based work and regular feedback moments, so the exchange of information becomes a source for action and reaction.

5. Ownership: If students (as well as teachers) have the impression that they are in control of the learning, there is a sense of ownership. This is an essential ingredient for motivation and self-organized learning.

6. Creativity: in creativity one can be honest and you are able to develop an identity. Through creative expressions one is able to have an idea about his or her capabilities and interests, which is fundamental for maintaining motivation and discovering one's talents.

7. Relevance: ownership of learning also means defining those topics that the learner finds relevant in life, even though this is not part of the official curriculum. Teachers should, as far is possible, allow students to define the topics they want to learn, research, do. The main objective is to add relevance and to foster curiosity about the topics the students want to cover.

\section{The Tools}

To prepare for the development of the methodology there was a needs analysis and an initial study of the students' profile and participating institutions in order to adapt the suggested collection of tools to the different contexts and the students' abilities and needs.

After the study a toolkit was established including a collection of social tools (Web 2.0) based on the concept of Personal Learning Environment (PLE). These tools support personalized learning; the learner is in control, produces (rather than consumes), and learning happens 
anywhere and anytime. The environment at the start of the project contained social media like Facebook, collaboration tools like Google Docs, presentation software like Prezi or Glogster, and utilities like Google Translator. The latter allows for a quick translation of the content of any web resource, which is vital for the collaboration between students from different countries with restricted language skills. Diigo, a social bookmarking tool, was used to publicly store all the links categorized using keywords, such as collaboration, presentation, storytelling, survey, and more. Participants can use, upgrade and add all kinds of helpful information to this source. The selection of the most appropriate tool was a more or less organic process within the context of a particular project or for a product.

\section{PILOTING THE METHODOLOGY}

The project comprises two pilot studies of each six months. The first pilot finished in March 2012, the second pilot will end in July 2012. The first pilot focused predominantly on the experiences of the learners, and the difficulties and advantages of the approach from their point of view. The second pilot will focus on teachers, and their needs and reactions with regard to the approach. The second pilot incorporates improvements suggested by the first. The partners selected the specific groups of students for the pilots a few months previous to the pilots, as the annual nature of this kind of training precludes a decision about this at the current time (18 months before the first pilot). The two pilots involved a cohort of roughly 15-25 learners and 2-7 trainers, in each country. The total number of participants in the pilots was about 300 learners and 50 trainers.

The planned activities in both Pilots included the following.

- Getting acquainted: In the first stage of use of the environment (PLE) a series of activities are designed to develop familiarity with the environment, both in its technological and social aspects, and facilitate the development of community among the students of the different institutions participating in the project. This included a short teacher-training program.

- Collaborative creative project: In this phase, participants formed teams to carry out their own project jointly with pupils from other schools, using the available tools. The prime goal of the project was to collaborate and create something unique. The students themselves defined what they want to do, with the only requirement to do it in collaboration with others, national and international.

- Support and reflection: Support was available throughout the process, both during projects and afterwards. The team of tutors, mostly teacher from the school or institution intervened whenever it seemed appropriate and timely in order to promote reflection with the students about the process.

- Collaborative project integration: This phase starts with the process of integrating the project with the main training activity. The process is similar to that of the first project, but this time the requirement is that the project loosely fits the subject area of the formal training program. This can be negotiated between students and teachers.
- Final integration process: At this stage the activity returns to the objectives and curriculum of the original training program. The idea however is that the learners have experienced other ways of learning and the teachers observing throughout will have seen the value of this, and incorporate other approaches in their teaching (the project team may suggest these).

Pilot 2: The second pilot repeats the first pilot but while the first focuses on the learners, the attention in the second pilot is on the teachers involved and the intention to subsequently prepare for the integration of the methodology into the formal curriculum.

\section{Use OF Social Media DuRING Pilot 1}

In this section, we elaborate on the types of social media tools and how both students and teachers have used them. As a general definition social media is an umbrella term for interactive, web-based tools that are usually either cheap (or free) and easy to use and focus on collaboration, communication, and user-generated content (Wikipedia).

Facebook did play a significant role in the project. The group chat on the Facebook group for all participants and teachers was extensively used (unfortunately, because in the second pilot the number of members exceeded 250 and it was disabled). Facebook is a platform that offers a number of benefits, and one of the main reasons for its high level of use in the project is its integration into everyday life of many of the participants. This led to a high level of online interaction between students from the same class, but also from different countries. The downside of this high level of interaction is that information tended to get lost very easily, which was seen as a major obstacle for managing the International collaboration. This was less of a problem for groups using separate Facebook groups for their projects.

The students chose topics including music, animals, cars, technology, regional cultures, photography and gastronomy and used various social media to create or share information. YouTube was by far the most popular 'sharing' tool about topics students were 'investigating'. Information was searched on Wikipedia and through Google. Glogster was a very popular tool to make online posters with others and share that online, Prezi was used to create dynamic presentations, and Slideshare and iSpring to make dynamic and audio-based online presentations from Powerpoint. Stripcreator.com was used to make online cartoons, some Italian learners used a blogging platform (Splinder) to create their own website, and Mind42.com was used for creating mindmaps. All these tools, and more (Flickr, Dipity, online whiteboard, Google Sites, Google Translator, Dropbox, etc.), were chosen by the students and teachers from the provided Diigo list, or because they were previously familiar with the tool. All project results are shared on the project's wiki and most of them on Facebook. Localization (or support pages in local language) of tools was mentioned as a problem, as well as the need to store or remember logins. Google Translate did not always work well, especially with the Greek and German language. 


\section{EXPERIENCES IN THE FIELD}

This section comprises a short reflection on the experiences half way through the project with general data from Pilot 1 . The data have been collected using online questionnaires for students and teachers, teacher logbooks, (online) interviews with the national coordinators of the pilots and the national reports that were developed by each country at the end of the pilot.

The emphasis in the first pilot was on the students and the evaluation focused therefore very much on the perception of the students regarding the seven principles of the reAct methodology. The objective of the methodology is to help the students to change their attitude, become open minded and develop a learning skill. Since the time for the reAct program is limited to four to six hours a week, we expected not to be able to measure any of these high level objectives, but to measure the perception of the students in relation to the seven principles.

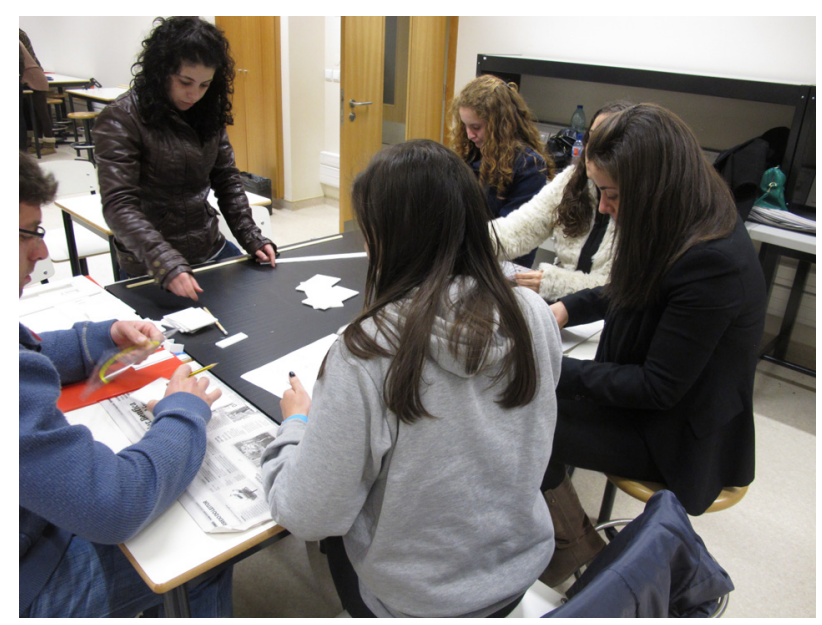

Figure 2. Evening class in Portugal

Students were asked (Q0) to indicate the importance of the reAct principles with regard to their own learning performance. The factors include trust in the teacher, in peer-students, being challenged, being able to influence and 'own' the learning, ability to collaborate with others, to express oneself creatively, the relevance of the learning for their own situation and/or interests, and the ability to use ICT. The factors were scored as Important to Very important between $65 \%$ (being able to collaborate) to $86 \%$ (Trust in the teacher and Trust in peer-students). Table one shows the summed average score for all answer options, whereby the negative answers were rated negatively, and positive answers positively (-2 for "Not important at all", 1 for "Not important", etc.). Relative importance is then scored, see table below using percentages. Although the results may not seem surprising, it shows that participating students, to a large degree, do indeed find these principles important for their own learning.

The questions on trust, challenge, ownership, etc., were repeated (Q1 \& 2), but this time the students were asked to reflect on the reAct project. The outcome was as follows:

- Trust teacher: around 66\% of the respondents have a (very) trustworthy relationship with the teachers (both for Q1 and Q2), and between 11\% (Q1) and $15 \%$ (Q2) do not (at all) have a trustworthy relationship with the teachers.
TABLE I.

RELEVANCE OF REACT PRINCIPLES FOR LEARNING

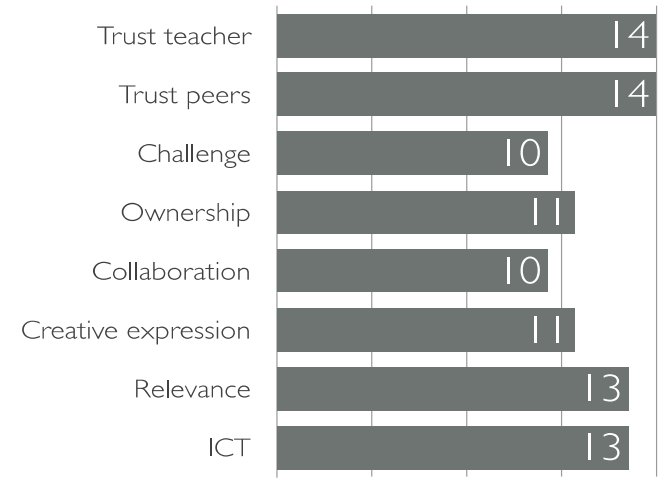

- Trust students: a slightly higher level of trust (and lower level of distrust) is measured between students, with more than $75 \%$ indicating a (high) trust level with other students.

- Challenged: around $40 \%$ of the respondents were very much challenged as there were respondents ambivalent to the statement (Neither agree nor disagree).

- $\quad$ Self-organization and ownership, being defined as the ability to decide what to learn, and how to learn. Since the reAct methodology also includes the stepwise "integration" into the regular schooling system it is not surprising that this "integration" (during the Q2 period) coincides with a drop of perceived "ownership" (from $71 \%$ to $56 \%$ ).

- Collaboration: more than $60 \%$ indicated that they collaborated with others in their projects, and about $10 \%$ did not.

- Creativity: just like ownership there was a slight drop (from $76 \%$ to $67 \%$ ) in the participants' ability to express creatively using various tools and instruments. This could relate to the "integration" of the reAct principles into the formal curriculum.

- Relevance: interestingly, the perceived 'relevance' of what learners learn (or are able to learn), increases slightly during the course, from $68 \%$ to $73 \%$. This could relate to the increased interest in learning by the learners, who might have widened their scope or interests during the course.

On the use of ICT: about $80 \%$ of the respondents indicate that they are using ICT, computers, and/or social media for their learning. From the national reports and logbooks, and our personal experiences in the local pilot, we can say the following about ICT usage. The most important tool has been Facebook, which was used as an 'always-on' and available platform for any student, teacher, or partner participating in the project.

The importance of collaboration was reflected in the question about if they liked to be part of an international project (see Table II).

In Q1 and Q2 the students were asked to rate their experience of the international project. The communication and organization of international collaboration between students who do not speak each other's language, and with little knowledge of English, was very hard. However, the 
TABLE II.

BEING PART OF AN INTERNATIONAL PROJECT

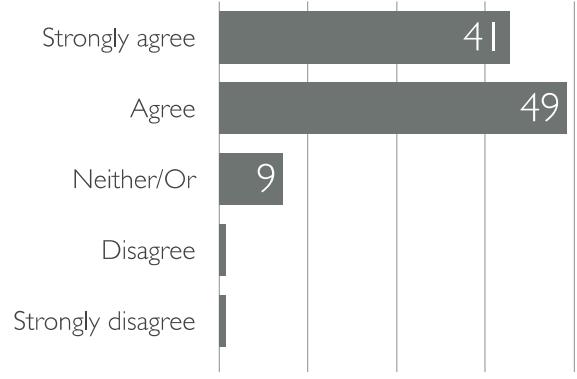

participating students were overwhelmingly positive (about 70\%), and only 3\% rated the experience negatively.

The overall experience of the students with the course was quite positive (70\% positive to Very positive) and only a fraction was negative (3-6\%) and no one 'Very Negative'. In addition the participants were asked how much the course influenced them for the following:

- $\quad$ Preparing for a job or internship: around 45\% thinks the course prepares them well for a job or internship, while between 23\% (Q1) and 30\% (Q2) does not agree.

- Communication and ability to connect with others: most respondents (around 67\%) think the course improves their capacity to communicate and connect with others.

- $\quad$ Confidence: while between 48\% (Q1) and 40\% (Q2) of respondents think the course has a positive influence on their confidence, there is a substantial group (resp. 15\% and 11\%) that "Do not agree at all" with this.

\section{CONCLUSIONS}

The experiences in the first pilot of the reAct project do not yet allow saying something about particular benefits or drawbacks of self-organized learning in this context, but the results show that students appreciate the confidence this approach mitigates and value the opportunity to be self-organized and experience learning autonomy. They value the collaboration especially in the international setting and believe that what they have learned is relevant for them to apply for a job, connect to others and have more confidence related to learning.

ICT is considered an important carrier for the execution of the reAct learning approach. Not just as a tool, but also as an instrument to attain goals set by yourself in collaboration with others, allowing communicating freely and delivering products that arose from your own motivation.

So far the results are promising, but not yet enough apparent to draw vital conclusions. It is clear from the reaction of the participants that the reAct methodology changed the attitude of the learners with regard to learn- ing. Learners are positive about the approach and feel that it opens up opportunities for further personal growth. Teachers get a better feel for and see more possibilities for promoting learning.

\section{ACKNOWLEDGMENT}

This paper could not have been written without the commitment of the partners and the students and teachers in this project. The authors want to thank them for their knowledgeable feedback and support.

\section{REFERENCES}

[1] EC Staff working Paper (2011) Reducing early school leaving. Proposal for a Council Recommendation on policies to reduce early school learning. COM (2011) 19 final.

[2] IRIS (2009) Thematic Study on Policy Measures concerning Disadvantaged Youth. Grade retention during compulsory schooling in Europe: Regulations and statistics 2009/2010. European Commission.

[3] European Commission (2008). Improving competences for the 21st Century - SEC (2008) 2177.

[4] Kendall \& Kinder (2005) Reclaiming those disengaged from education and learning: a European Perspective.

[5] Rumberger, R., and Lim, S., (2008) "Why Students Drop Out of School: A Review of 25 Years of Research", California Dropout Research Project, University of California, Santa Barbara.

[6] Veen, W., Van Staalduinen, J.P. \& Hennis, T. (2010) In: Giuliana Dettori, Donatella Persico (Eds.) Fostering Self-regulated learning through ICTs. pp. 364-379. IGI Global, Hershey PA, USA. ISBN 9781616929015. http://dx.doi.org/10.4018/978-1-61692901-5.ch022

[7] Wilson, S., Liber, O., Johnson, M., Beauvoir, P., Sharples, P., \& Milligan, C. (2009). Personal Learning Environments: Challenging the dominant design of educational systems. Journal of $e$ Learning and Knowledge Society, 3(2).

[8] Hennis, T., Veen, W. \& Staalduinen, J.P. (2011). reAct Methodological Approach Guidelines. Valencia, Spain. (see www.reactproject.eu)

[9] De Vries, P. \& Van den Bogaard, M. (2009). A Contemporary Educational Model for Life Long Learning Practices. In: Lappalainen, P. ; Oy, Langwitch (2009). European Continuing Engineering Education, conceptualizing the lessons learned. Finland, SEFI and TKK Dipoli. Pp. 209-218.

[10] Ferrando, A., De Vries, P., Ruiz, C., Hennis, T. (2012). Reactivating Demotivated Learners - The ReAct Approach. INTED conference proceedings, Sevilla, Spain.

\section{AUTHORS}

Pieter de Vries is with the Systems Engineering Department of the Delft University of Technology. P.O. Box 5015, 2600 GA Delft, The Netherlands (e-mail: pieter.devries@tudelft.nl).

Thieme Hennis is with the Systems Engineering Department of the Delft University of Technology. P.O. Box 5015, 2600 GA Delft, The Netherlands (e-mail: t.a.hennis@tudelft.nl).

This work was supported in part by the European Commission under Grant contract $n^{\circ}$ 511709-LLP-1-2010-1-ES-KA3-KA3MP. Received 7 Mai 2012. Published as resubmitted by the authors 11 February 2013 